\title{
Fracionamento de carboidratos de silagem de capim-elefante emurchecido ou com farelo de cacau ${ }^{1}$
}

\section{Gleidson Giordano Pinto de Carvalho², Rasmo Garcia ${ }^{3,7}$, Aureliano José Vieira Pires ${ }^{4,7}$, Odilon Gomes Pereira 3 ,7, Francisco Éden Paiva Fernandes ${ }^{5}$, José Antônio Obeid ${ }^{3}$, Bruna Mara Aparecida de Carvalho 6}

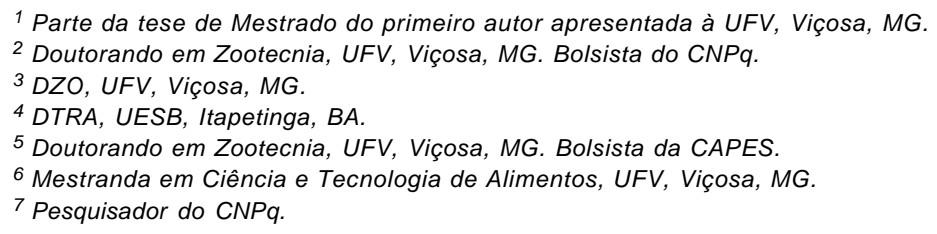

RESUMO - O experimento foi conduzido para determinar as frações que compõem os carboidratos da silagem de capimelefante emurchecido ou acrescida de farelo de cacau. O capim-elefante utilizado foi colhido aos 50 dias de rebrota após o corte de uniformização e submetido aos seguintes tratamentos: capim-elefante emurchecido ao sol por oito horas e capim-elefante não-emurchecido acrescido de $0,7,14,21$ e $28 \%$ de farelo de cacau (\% da matéria natural). O material foi acondicionado em silos de PVC com capacidade para 5,3 L, que foram abertos após 45 dias. A silagem de capim emurchecido apresentou teor de carboidratos totais (CT) semelhante ao daquelas com 14 e $21 \%$ de farelo de cacau. A análise de regressão detectou redução linear desta fração nas silagens com farelo de cacau. Para todas as frações de carboidratos estimadas, a silagem de capim emurchecido apresentou valores semelhantes ao daquela com capim sem emurchecimento. As frações dos carboidratos totais das silagens foram influenciadas pela adição de farelo de cacau, de modo que os teores de A+B1 e FDNi aumentaram e os de B2 diminuíram com a inclusão de farelo de cacau.

Palavras-chave: conservação de forragens, forrageira, Pennisetum purpureum, subproduto, Theobroma cacao L.

\section{Carbohydrate fractioning of elephantgrass silage wilted or enriched with cocoa meal}

\begin{abstract}
The experiment was carried out to determine the carbohydrate fractions of elephantgrass silage wilted under the sun for eight hours. Other treatments included the same elephantgrass without wilting but with addition of $0,7,14$, 21 , and $28 \%$ of cocoa meal at the ensiling process. The PVC silos used in the experiment had $5.3 \mathrm{~L}$ of capacity, and they were opened 45 days after ensiling. The wilted treatment showed total carbohydrate (TC) concentration similar to treatments with 14 and $21 \%$ cocoa meal. The regression analysis detected linear reduction of this fraction with the addition of cocoa meal. For all carbohydrate estimated fractions, the wilted treatment showed similar values to the treatment without wilting. The silage TC fractions were altered by cocoa meal addictions, presenting high concentration of $\mathrm{A}+\mathrm{B} 1$, and NDFi, and low concentration of B2 with increasing cocoa meal level.
\end{abstract}

Key Words: by-product, forage conservation, roughage, Pennisetum purpureum, Theobroma cacao L.

\section{Introdução}

A baixa produção bovina nos trópicos pode ser atribuída, principalmente, à nutrição inadequada resultante da sazonalidade característica da produção forrageira nestas condições. Em um programa de produção contínua de carne, é essencial eliminar as fases negativas de desenvolvimento e proporcionar condições para o animal desenvolver-se normalmente, durante todo o ano, para que alcance condições de abate, peso e/ou terminação em idade mais precoce (Euclides et al., 1998). Para isso, é necessário manter o suprimento de alimento em equilíbrio com as exigências dos animais, por meio da suplementação volumosa, com destaque para os alimentos conservados, os fenos e as silagens.

Entre as forrageiras com potencial para produção de alimentos conservados, o capim-elefante, tradicionalmente utilizado para corte em capineiras, destaca-se como forrageira para ensilagem. Seu uso é indicado principalmente em razão da elevada produção de MS e de seu valor nutritivo 
(A ndrade \& Lavezzo, 1998). Entretanto, no mo mento em que apresenta melhor valor nutritivo, o teor de umidade do capim-elefante normalmente é elevado, o que contraria as exigências para produção de silagem de boa qualidade. A ensilagem de gramíneas com elevado teor de umidade favorece as perdas durante as diferentes fases do processo (Bernardino et al., 2005) e propicia o desenvolvimento de bactérias do gênero Clostridium, favorecido pela alta atividade da água, em virtude do excesso de umidade da forragem. O desenvolvimento dessas bactérias produz fermentações secundárias indesejáveis e promove a formação de ácido butírico, caracterizando silagens de baixa qualidade, com degradação de proteína e de ácido lático (McDonald, 1981).

O farelo de cacau, subproduto do beneficiamento da amêndoa do cacau para produção de manteiga e chocolate pelas indústrias, tem sido empregado com sucesso na alimentação de ruminantes como substituto aos alimentos concentrados (milho e farelo de soja). Carvalho et al. (2006), Pires et al. (2005) e Silva et al. (2005) recomendaram, respectivamente, a adição de 12,15 e $18 \%$ de farelo de cacau na dieta total de ovinos, bovinos e caprinos.

Segundo Fox et al. (1992), os sistemas atuais de adequação de dietas para ruminantes necessitam de informações sobre as frações de carboidratos dos alimentos para estimativas mais exatas do desempenho dos animais e maximização da eficiência de utilização dos nutrientes.

Assim, a caracterização das frações que constituem os carboidratos dos alimentos obtidos em condições tropicais constitui instrumento valioso para formulação de dietas visando à maximização do crescimento microbiano ruminal e, conseqüentemente, a melhor predição do desempenho dos animais.

Desse modo, objetivou-se com este experimento determinar as frações que compõem os carboidratos de silagens de capim-elefante Pennisetum purpureum, Schum. cv. Napier) emurchecido ou acrescido de diferentes níveis de farelo de cacau (Theobroma cacao L.).

\section{Material e Métodos}

Utilizou-se o capim-elefante (Pennisetum purpureum, Schum.cv. Napier) proveniente de uma capineira estabelecida em um solo classificado como chernossolo argilúvio, ótico, típico, estruturado hipereutrófico, com textura argilosa, fase floresta subcaducifólia e relevo ondulado (EMBRAPA, 1999), pertencente à Universidade Estadual do Sudoeste da Bahia, UESB, Itapetinga, BA.

O capim foi submetido ao corte de uniformização com altura média de $10 \mathrm{~cm}$ do solo e, após 50 dias de rebrota, foi colhido manualmente e picado em fragmentos de $2 \mathrm{~cm}$ em ensiladeira estacionária e ensilado conforme os seguintes tratamentos: capim-elefante emurchecido ao sol por 8 horas; capim-elefante não-emurchecido; capim-elefante $(93 \%)+$ farelo de cacau (7\%); capim-elefante $(86 \%)+$ farelo de cacau $(14 \%)$; capim-elefante $(79 \%)+$ farelo de cacau $(21 \%)$; e capim-elefante $(72 \%)+$ farelo de cacau $(28 \%)$.

No processo de emurchecimento, o capim foi colhido e espalhado no campoe, após 8 horas de exposição ao sol, foi picado e ensilado. A mistura de farelo de cacau ao capimelefante não-emurchecido foi realizada logo após o fracionamento do capim, proporcionalmente à massa verde (peso/peso) da forrageira. A composição químicobromatológica do capim-elefante e do farelo de cacau antes da ensilagem foi obtida segundo metodologia descrita por Silva \& Queiroz (2002).

O material foi ensilado em silos experimentais de PVC, cilíndricos, com $0,15 \mathrm{~m}$ de diâmetro e $0,3 \mathrm{~m}$ de comprimento e capacidade para 5,3 L, adotando-se compactação de $500 \mathrm{~kg} / \mathrm{m}^{3}$. Os silos foram vedados com lona plástica nas duas extremidades, utilizando-se arame liso galvanizado e fita plástica, e armazenados em galpão coberto durante 45 dias.

Após abertura dos silos, procedeu-se à coleta de amostras, que foram congeladas para posteriores análises. As amostras foram devidamente acondicionadas, transportadas para o Departamento de Zootecnia da Universidade Federal de Viçosa, onde foram processadas e analisadas nos Laboratórios de Forragicultura e Nutrição Animal. Parte das amostras foi descongelada à temperatura ambiente, acondicionada em sacos de papel, mantida em estufa de présecagem (durante 72 horas a $65^{\circ} \mathrm{C}$ ) e triturada em moinho tipo Willey com peneira de malha de $1 \mathrm{~mm}$.

A porcentagem de carboidratos totais (CT) foi obtida pela equação (Sniffen et al., 1992): CT $=100-(\% \mathrm{~PB}+\% \mathrm{EE}$ $+\%$ cinzas). Os carboidratos fibrosos (CF) foram obtidos a partir da FDN corrigida para cinzas e proteínas $\left(\mathrm{FDN}_{\mathrm{CP}}\right)$; os $\mathrm{CNF}$, correspondentes às frações $\mathrm{A}+\mathrm{B} 1$, pela diferença entre os CT e a FDN $\mathrm{CP}_{\mathrm{CP}}$ (Hall, 2003); e a fração C, pela FDN indigestível após 144 horas de incubação in situ (Cabral et al., 2004). A fração B2, correspondente à fração disponível da fibra, foi obtida pela diferença entre a $\mathrm{FDN}_{\mathrm{CP}}$ e a fração $C$.

O delineamento experimental adotado foi o inteiramente casualizado, com seis tratamentos e quatro repetições. O efeito dos níveis de farelo de cacau foi interpretado por análises de variância e de regressão e a comparação entre os níveis de farelo de cacau e o emurchecimento foi realizada conforme Dunnett (1955), a 5\% de probabilidade, utilizando-se o Statistical Analyses System (SAS, 1999). 


\section{Resultados e Discussão}

A composição químico-bromatológica do capim-elefante emurchecido, sem emurchecimento e do farelo de cacau antes da ensilagem pode ser observada na Tabela 1.

Os teores de carboidratos totais (CT) diferiram entre as silagens (Tabela 2); naquelas produzidas com capim-elefante não-emurchecido ou acrescidas de $7 \%$ de farelo de cacau, os teores de CT foram superiores $(\mathrm{P}<0,05)$ aos obtidos na silagem de capim emurchecido. As demais silagens acrescidas de farelo de cacau $(14,21$ e $28 \%)$ apresentaram valores de carboidratos totais similares $(\mathrm{P}>0,05)$ ao da silagem de capimemurchecido.

Os níveis de farelo de cacau promoveram redução linear no teor de carboidratos totais, que diminuiu 0,22 percentuais a cada unidade de farelo de cacau (FC) adicionada, segundo a equação $\hat{Y}=81,3980-0,22168^{* *}$ FC (Figura 1).

Uma vez que o farelo de cacau apresentou teores de PB e EE, respectivamente, 36 e $83 \%$ superiores ao do capimelefante (Tabela 1), é possível que a redução no teor de carboidratos totais das silagens com farelo de cacau tenha sido ocasionada pelo elevado teor destas frações, pois, na estimativa do teor de CT, segundo Sniffen et al. (1992),

Tabela 1 - Composição química e nutricional, pH e digestibilidade in vitro da MS (DIVMS) do capim-elefante e do farelo de cacau

Table 1 - Chemical composition, $\mathrm{pH}$, and in vitro dry matter digestibility (IVDMD) of elephantgrass and cocoa meal

\begin{tabular}{|c|c|c|c|}
\hline \multirow[t]{2}{*}{ Item } & \multicolumn{2}{|c|}{$\begin{array}{l}\text { Capim-elefante } \\
\text { Elephantgrass }\end{array}$} & \multirow[t]{2}{*}{$\begin{array}{l}\text { Farelo de cacau } \\
\text { Cocoa meal }\end{array}$} \\
\hline & $\begin{array}{l}\text { Jão-emurchecido } \\
\text { Not wilted }\end{array}$ & $\begin{array}{c}\text { Emurchecido } \\
\text { Wilted }\end{array}$ & \\
\hline $\mathrm{MS}(D M)$ & 20,1 & 27,8 & 89,8 \\
\hline $\mathrm{MO}^{1}(\mathrm{MO})$ & 90,4 & 90,2 & 92,6 \\
\hline $\mathrm{PB}^{1}(C P)$ & 8,6 & 8,5 & 13,5 \\
\hline $\mathrm{EE}^{1}$ & 1,7 & 1,8 & 9,9 \\
\hline $\mathrm{FDN}^{1}(N D F)$ & 71,1 & 68,6 & 48,5 \\
\hline $\mathrm{FDNcp}^{1}\left(N D F_{A P}\right)$ & 67,5 & 65,2 & 43,6 \\
\hline $\mathrm{FDA}^{1}(A D F)$ & 43,6 & 41,3 & 40,0 \\
\hline $\operatorname{Cinza}^{1}($ Ash $)$ & 9,6 & 9,8 & 7,4 \\
\hline Lignina $^{1}$ (lignin) & 3,3 & 3,3 & 17,9 \\
\hline Celulose $e^{1}$ (cellulose) & 40,3 & 37,9 & 23,1 \\
\hline Hemicelulose $\mathrm{e}^{1}$ & 27,4 & 27,3 & 8,5 \\
\hline \multicolumn{4}{|l|}{ Hemicellulose } \\
\hline $\operatorname{NIDN}^{1}(N D I N)$ & 0,21 & 0,23 & 1,1 \\
\hline $\mathrm{NIDA}^{1}(A D I N)$ & 0,15 & 0,16 & 1,0 \\
\hline $\mathrm{NIDN}^{2}(N D I N)$ & 15,2 & 16,9 & 50,5 \\
\hline $\mathrm{NIDA}^{2}(A D I N)$ & 10,8 & 11,8 & 47,7 \\
\hline $\mathrm{CT}^{1}(T C)$ & 80,1 & 79,9 & 69,2 \\
\hline $\mathrm{CNF}^{1}(N F C)$ & 12,6 & 14,4 & 25,7 \\
\hline $\mathrm{CHOs}^{1}$ (CHOs) & 10,9 & 10,2 & 12,2 \\
\hline $\mathrm{pH}$ & 5,6 & 5,6 & - \\
\hline $\operatorname{DIVMS}^{1}(I V D M D)$ & 63,5 & 64,2 & 47,0 \\
\hline
\end{tabular}

$1 \%$ da MS; ${ }^{2} \%$ do nitrogênio total ( $1 \% D M ;{ }^{2} \%$ total nitrogen). $\mathrm{CHOs}=$ carboidratos solúvies quanto maiores os teores de PB e EE, menor a proporção de carboidratos.

As frações de carboidratos, A+B1, B2 e C (FDNi), e suas respectivas equações de regressão são apresentadas nas Figuras 2, 3 e 4.

A fração $A+B 1$ dos carboidratos não diferiu $(\mathrm{P}>0,05)$ entre as silagens, o que pode estar associado ao teor de $\mathrm{FDN}_{\mathrm{CP}}$, que foi semelhante entre as silagens (Tabela 1). Contudo, os valores observados para as silagens de capimelefante com 7, 14, 21 e $28 \%$ de farelo de cacau foram superiores $(\mathrm{P}<0,05)$ ao da silagem de capim emurchecido (Tabela 2). As maiores frações solúveis em detergente neutro (A+B1) observadas nas silagens com farelo de cacau resultaram do menor teor de $\mathrm{FDN}_{\mathrm{CP}}$ do farelo de cacau em relação ao capim-elefante.

A adição de níveis crescentes de farelo de cacau ao capim-elefante promoveu acréscimo linear na fração A+B1 (Figura 1), estimado em 6,0;10,9; 14,2 e 15,5 unidades percentuais, respectivamente, para as silagens com 7, 14, 21 e $28 \%$ de farelo de cacau em comparação àquela sem farelo. Esse acréscimo provavelmente ocorreu em virtude dos maiores de teores de CNF do farelo de cacau.

$\mathrm{O}$ valor de $\mathrm{A}+\mathrm{B} 1$ (em \% dos $\mathrm{CT}$ ) obtido para a silagem de capim-elefante sem farelo de cacau foi próximo ao determinado por Malafaia et al. (1998) no capim-elefante. Contudo, nas silagens com farelo de cacau, estimou-se que, a partir do nível de 14\%, o teor da fração A+B1 (\% CT) foi superior a $20 \%$, próximo ao encontrado por Malafaia et al. (1998) em silagem de milho, indicando que a utilização de farelo de cacau na ensilagem do capim-elefante provocou aumento da fração A+B1.

Alimentos com elevada proporção da fração $\mathrm{A}+\mathrm{B} 1$ são considerados boas fontes de energia para o crescimento de microrganismos que utilizam CNF. Contudo, é necessária a inclusão de fontes protéicas de rápida e média degradação no rúmen quando a fração $\mathrm{A}+\mathrm{B} 1$ compõe a principal fração dos carboidratos da dieta objetivando a sincronização entre a liberação de energia e nitrogênio (Valadares Filho, 2000).

Quanto à fração B2 (\% CT), correspondente aos carboidratos fibrosos potencialmente digestíveis, apenas a silagem sem farelo de cacau foi similar $(\mathrm{P}>0,05)$ àquela com capim emurchecido. Nas silagens com 7, 14, 21 e $28 \%$ de farelo de cacau, a fração B2 foi significativamente inferior $(\mathrm{P}<0,05)$ à da silagem produzida com capim-elefante emurchecido (Tabela 2). No estudo de regressão, verificou-se decréscimo linear nos valores de B2 conforme aumentaram os níveis de farelo de cacau (Figura 1). Possivelmente, o menor teor de FDN do farelo de cacau em relação ao do capim-elefante (Tabela 1) causou essa redução. 
Tabela 2 - Teores médios de carboidratos totais (CT), CNF (A+B1), componentes da parede celular disponíveis, correspondentes à fração potencialmente degradável (B2), e fração indigestível da parede celular (FDNi) de silagens de capim-elefante emurchecido (EMUR) ou não-emurchecido acrescido de farelo de cacau

Table 2 - Mean concentration of total carbohydrates (TC), non-fiber carbohydrates $(A+B 1)$, cell wall available components, which correspond to cell wall potentially degradable fraction (B2) and indigestible fraction (NDFi), of elephant grass silages wilted (WIL) and not wilted but enriched with cocoa meal

\begin{tabular}{|c|c|c|c|c|c|c|c|}
\hline \multirow[t]{2}{*}{ Item } & \multirow[b]{2}{*}{$\begin{array}{l}\text { EMUR } \\
\text { Wilted }\end{array}$} & \multicolumn{5}{|c|}{$\begin{array}{l}\text { Farelo de cacau }(\%) \\
\quad \text { Cocoa meal }\end{array}$} & \multirow[t]{2}{*}{$\mathrm{CV}(\%)$} \\
\hline & & 0 & 7 & 14 & 21 & 28 & \\
\hline \multirow{2}{*}{$\begin{array}{l}\mathrm{CT}(\% \mathrm{MS}) \\
T C(D M \%)\end{array}$} & 76,8 & $81,8^{*}$ & $79,6^{*}$ & 77,8 & 76,9 & 75,4 & 1,2 \\
\hline & & \multicolumn{5}{|c|}{$\begin{array}{c}\text { Fração de carboidratos (\% CT) } \\
\text { Carbohydrate fraction }(T C \%)\end{array}$} & \\
\hline $\mathrm{A}+\mathrm{B} 1$ & 12,3 & 10,7 & $16,8^{*}$ & $21,6^{*}$ & $25,0^{*}$ & $26,2^{*}$ & 10,8 \\
\hline B2 & 55,1 & 58,6 & $49,6^{*}$ & $43,9^{*}$ & $39,9^{*}$ & $37,0^{*}$ & 4,1 \\
\hline FDNi & 32,6 & 30,7 & 33,6 & 34,5 & 35,1 & $36,8^{*}$ & 4,7 \\
\hline
\end{tabular}

*As médias seguidas por asterisco diferem da testemunha a $5 \%$ de probabilidade pelo teste Dunnett.

* Means followed by asterisk differ from the control at $5 \%$ probability level by Dunnett test. $\mathrm{CV}=$ Coeficiente de variação (Coefficient of variation).
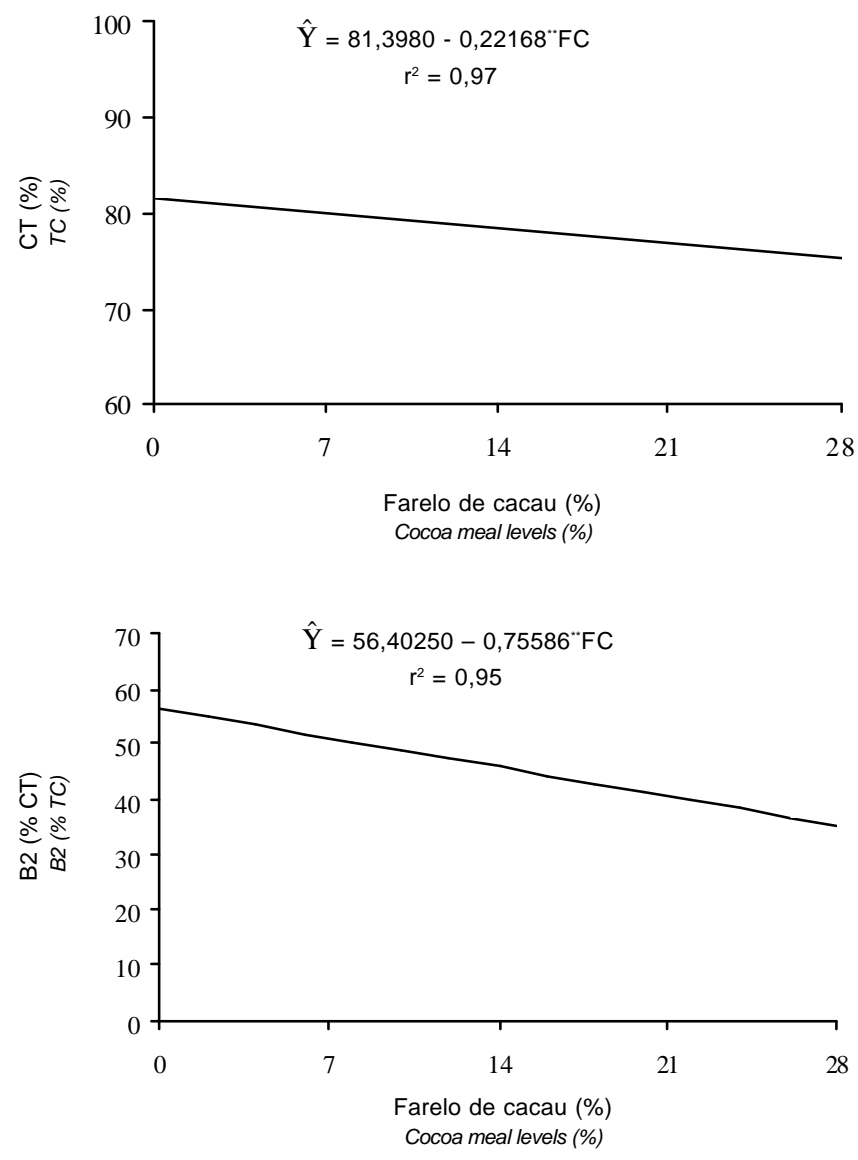

Malafaia et al. (1998) destacaram que o valor da fração B2 dos alimentos está relacionado ao teor de FDN, pois, em estudos realizado por esses autores com diversos alimentos, ficou evidenciado que as gramíneas foram os volumosos com os maiores valores da fração B2, em decorrência de seus mais altos valores de FDN. Esses maiores valores da fração B2 em relação às frações $\mathrm{A}+\mathrm{B} 1 \mathrm{e} \mathrm{C}(\mathrm{FDNi})$, para todas as silagens testadas, estão de acordo com os observados por Malafaia \& Vieira (1997) nos capins tifton 85, elefante, braquiarão e braquiária, na silagem de milho e no feno de coast-cross.

Os valores da fração B2 (\% CT) observados neste experimento para as silagens de capim-elefante sem farelo de cacau $(55,1$ e 58,6\%, respectivamente para as silagens de capim emurchecido e não-emurchecido) corroboram o valor da fração B2 (\% CT), de 51,7\%, relatado por Cabral et al. (2004) para a silagem de capim-elefante. Esse resultado está relacionado às características químicas do capim-elefante utilizado neste trabalho (Tabela 1), que foram semelhantes às do capim utilizado por esses autores, principalmente quanto aos teores de MS, CT e FDN.
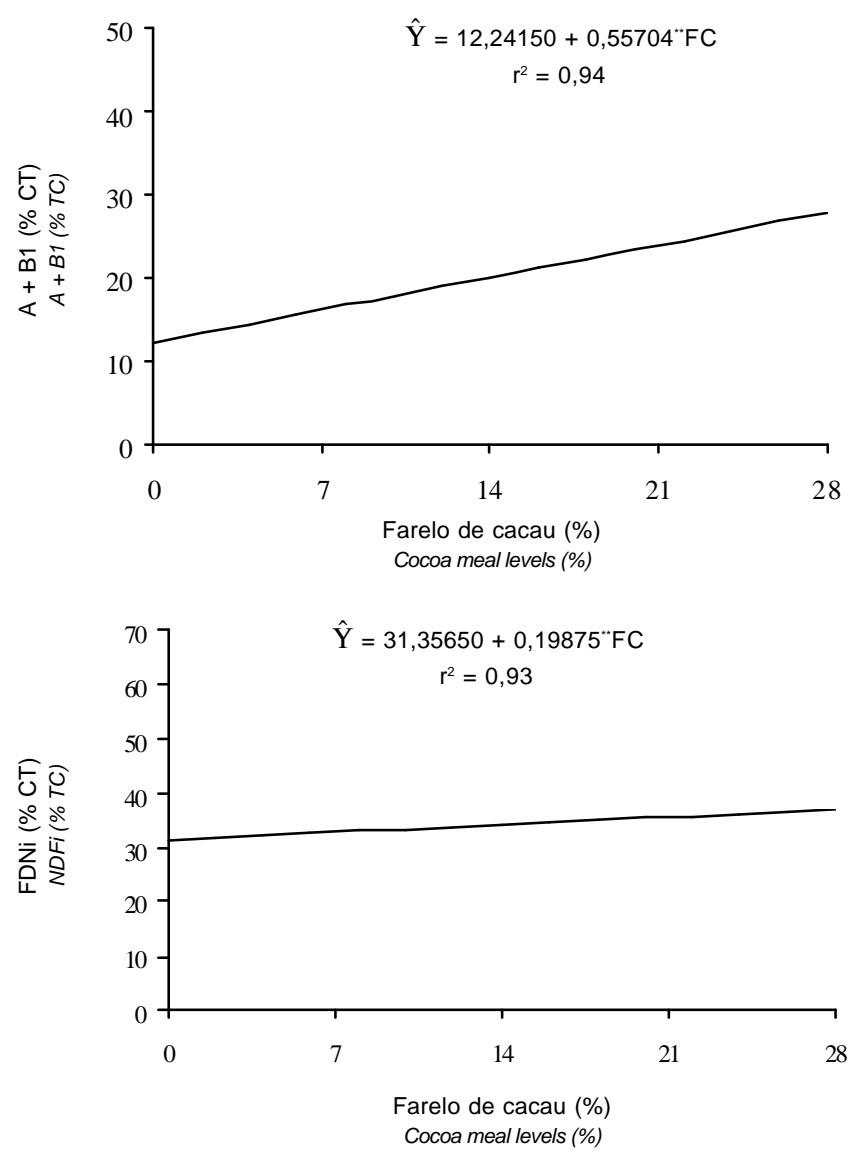

Figura 1 - Estimativa dos teores de carboidratos totais (CT) e das frações A+B1, B2 e FDNi (\% CT) das silagens em função de diferentes níveis de farelo de cacau (FC) ${ }^{\star *}$ Significativo a $1 \%$ de probabilidade pelo teste $F$.

Figure 1 - Estimate of total carbohydrates (CT) and of A+B1, B2 and FDNi fractions (CT\%) contents of silages as function of different levels of cocoa meal (CM)** Significant at $1 \%$ probability by $F$ test. 
A fração $\mathrm{B} 2$, principal componente da silagem de capim-elefante, independentemente da adição de farelo de cacau, por apresentar lenta taxa de degradação, juntamente com a fração C (indigestível) normalmente afeta o consumo animal pelo fator enchimento, reduzindo o desempenho dos animais (Mertens, 1987).

Não houve diferença $(\mathrm{P}>0,05)$ entre as silagens (Tabela 2) quanto à fração $\mathrm{C}$ dos carboidratos, representada pela FDNi, entretanto, como demonstrado na Figura 1, o estudo de regressão mostrou efeito $(\mathrm{P}<0,01)$ dos níveis de farelo de cacau sobre a FDNi.

Uma vez que a FDNi inclui a porção da parede celular vegetal que não é digerida ao longo do trato gastrintestinal (Sniffen et al., 1992), é possível que o acréscimo desta fração com o aumento dos níveis de farelo de cacau tenha sido ocasionado pelo elevado teor de lignina no farelo de cacau $(17,9 \%$ ) (Tabela 1$)$, visto que a lignina é constituída de um polímero fenólico associado aos carboidratos estruturais, à celulose e à hemicelulose (Norton, 1982) e consiste no componente que mais limita a digestão dos polissacarídeos da parede celular no rúmen (Jung \& Deetz, 1993).

Os teores de FDNi das silagens de capim-elefante emurchecido e não emurchecido (respectivamente, 32,6 e $30,7 \%$ ) estão de acordo com o de $33,6 \%$ observado por Cabral et al. (2004) em silagem de capim-elefante. Torna-se evidente, portanto, que os maiores valores da FDNi nas silagens com farelo de cacau foram ocasionados pela adição desse resíduo na ensilagem.

Apesar do aumento da fração $\mathrm{C}$, a fração B2 foi a principal fração nas silagens com farelo de cacau, o que torna esse subproduto uma alternativa de fonte de carboidratos potencialmente digeríveis.

\section{Conclusões}

A utilização de capim-elefante emurchecido por exposição ao sol melhora a composição em carboidratos da silagem. Os elevados teores de extrato etéreo e os teores moderados de proteína bruta do farelo de cacau diminuem o teor de carboidratos totais das silagens. A fração A+B 1 representa menos de $15 \%$ dos carboidratos da silagem de capim-elefante, contudo, valores superiores a $20 \%$ podem ser obtidos com adição de $14 \%$ de farelo de cacau na ensilagem. A utilização de farelo de cacau na ensilagem de capim-elefante aumenta a proporção de carboidratos indigeríveis das silagens, entretanto, a fração B2 constitui importante fonte de energia.

\section{Literatura Citada}

ANDRADE, J.B.; LAVEZZO, W. Aditivos na ensilagem do capimelefante. I. Composição bromatológica das forragens e das respectivas silagens. Pesquisa Agropecuária Brasileira, v.33, n.11, p.1859-1872, 1998.

BERNARDINO, F.S.; GARCIA, R.; ROCHA, F.C. et al. Produção e características do efluente e composição bromatológica da silagem de capim-elefante contendo diferentes níveis de casca de café Revista Brasileira de Zootecnia, v.34, n.6, p.2185-2291, 2005.

CABRAL, L.S.; VALADARES FILHO, S.C.; DETMANN, E. et al. Taxas de digestão das frações protéicas e de carboidratos para as silagens de milho e de capim-elefante, o feno de capimtifiton-85 e o farelo de soja. Revista Brasileira de Zootecnia, v.33, n.6, p.1573-1580, 2004.

CARVALHO, G.G.P.; PIRES, A.J.V.; VELOSO, C.M. et al. Desempenho e digestibilidade de ovinos alimentados com farelo de cacau (Theobroma cacao L.) em diferentes níveis de substituição. Ciência Animal Brasileira, v.7, n.2, p.115-122, 2006.

DUNNETT, C.W. A multiple comparison procedure for comparing several treatments with control. Journal American State Association, v.50, n.272, p.1096-1121, 1955.

EMPRESA BRASILEIRA DE PESQUISA AGROPECUÁRIA EMBRAPA. Sistema brasileiro de classificação de solos. Brasília: EMBRAPA, 1999. 412p.

EUCLIDES, V.P.B.; EUCLIDES FILHO, K.; ARRUDA, Z.J. et al. Desempenho de novilhos em pastagens de Brachiaria decumbens submetidos a diferentes regimes alimentares. Revista Brasileira de Zootecnia, v.27, n.2, p.246-254, 1998.

FOX, D.G.; SNIFFEN, C.J.; O'CONNOR, J.D. et al. A net carbohydrate and protein system for evaluating cattle diets: III. Cattle requeriments and diet adequacy. Journal Animal Science, v.70, n.12, p.3578-3596, 1992.

HALL, M.B. Challenges with nonfiber carbohydrate methods. Journal of Animal Science, v.81, p.3226-3232, 2003.

JUNG, H.G.; DEETZ, D.A. Cell wall lignification and degradability. In: JUNG, H.G.; BUXTON, D.R.; HATIFIELD, R.D. et al. (Eds.) Forage cell wall structure and digestibility. Madison: America Society of Agronomy, Crop Science Society of America, Soil Sci. Society of America, 1993. p.315-46.

MALAFAIA, P.A.M.; VIEIRA, R.A.M. Técnicas de determinação e avaliação dos compostos nitrogenados em alimentos para ruminantes. In: SIMPÓSIO INTERNACIONAL DE DIGESTIBILIDADE EM RUMINANTES, 1997, Lavras. Lavras: UFLA - FAEPE, 1997. p.29-54.

MALAFAIA, P.A.M.; VALADARES FILHO, S.C.; VIEIRA, R.A.M. et al. Determinação das frações que constituem os carboidratos totais e da cinética ruminal da fibra em detergente neutro de alguns alimentos para ruminantes. Revista Brasileira de Zootecnia, v.27, n.4, p.790-796, 1998.

McDONALD, P. The biochemistry of silage. Nova York: John Wiley \& Sons, 1981. 226p.

MERTENS, D.R. Predicting intake and digestibility using mathematical models of ruminal function.Journal of Animal Science, v.64, n.5, p.1548-1558, 1987.

NORTON, B.W. Differences between species in forage quality. In: HACKER, J.B. (Ed.). Nutritional limits to animal production from pastures. Farnham Royal: Commonwealth Agricultural Bureaux, 1982. p.89-110.

PIRES, A.J.V.; VIEIRA, V.F.; SILVA, F.F. et al. Níveis de farelo de cacau (Theobroma cacao) na alimentação de bovinos. Revista Electrónica de Veterinária, v.6, n.2, p.1-10, 2005.

STATISTICAL ANALYSES SYSTEM - SAS. SAS user's guide. Cary: 1999. v.8, 295p.

SILVA, D.J.; QUEIROZ, A.C. Análise de alimentos: métodos químicos e biológicos. Viçosa, MG: Editora UFV, 2002. 235p. 
SILVA, H.G.O.; PIRES, A.J.V.; SILVA, F.F. et al. Farelo de cacau (Theobroma cacao L.) e torta de dendê (Elaeis guineensis, Jacq) na alimentação de cabras em lactação: consumo e produção de leite. Revista Brasileira de Zootecnia, v.34, n.5, p.1790$1798,2005$.

SNIFFEN, C.J.; O'CONNOR, D.J.; Van SOEST, P.J. et al. A net carbohydrate and protein system for evaluating cattle diets: carbohydrate and protein availability. Journal of Animal Science, v.70, n.12, p.3562-3577, 1992.
VALADARES FILHO, S.C. Nutrição, avaliação de alimentos e tabelas de composição de alimentos para bovinos. In: REUNIÃO ANUAL DA SOCIEDADE BRASILEIRA DE ZOOTECNIA, 37. 2000, Viçosa, MG. Anais... Viçosa, MG: Sociedade Brasileira de Zootecnia, 2000. p.267.

Recebido: 22/08/06 Aprovado: 09/02/07 